rev.relac.int.estrateg.segur.13(1):35-66,2018

\title{
Los desafíos de América Latina para proyectarse como actor regional en el ámbito de la seguridad internacional ${ }^{*}$
}

Sonia Alda Mejías ${ }^{* *}$

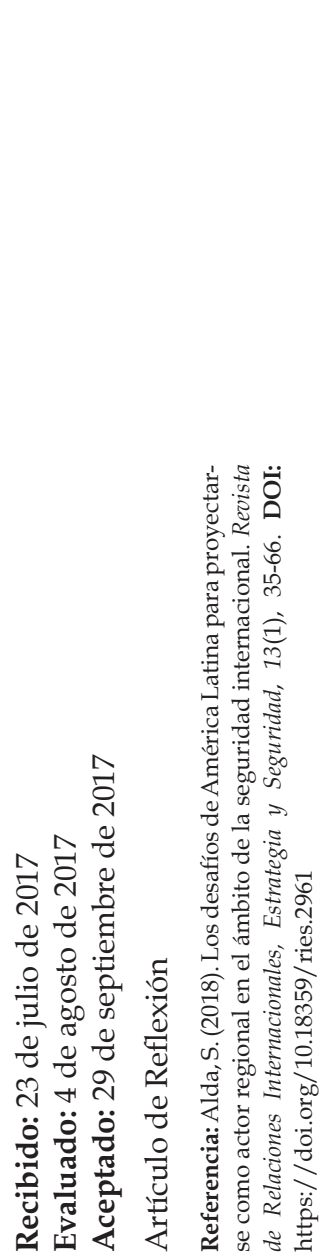

\section{Resumen}

En este trabajo se contempla la posibilidad de América Latina para proyectarse como actor regional en el ámbito de la seguridad internacional. Para alcanzar este objetivo, desde una metodología cualitativa, se han contemplado diferentes referencias que se entienden como requisitos necesarios: el proceso de integración subregional o regional y el desarrollo de la cooperación multilateral intra e internacional en el ámbito de la seguridad y la defensa, y la participación de los países latinoamericanos en las misiones internacionales de paz. En la evaluación de cada uno de estos aspectos es evidente la concepción de una perspectiva soberanista, por parte de los países de la región, muy marcada. De ahí que, pese a los avances evidentes logrados,

\footnotetext{
Este artículo surge del Centro de Estudios del Real Instituto Elcano, Madrid, España, dentro del Observatorio de Tráficos llegales y Redes Criminales.

** Doctora, Universidad Autónoma de Madrid y experta en seguridad y defensa. Investigadora asociada y directora del Observatorio de Tráficos llegales y Redes Criminales del Real Instituto Elcano. Es profesora en el Departamento de Relaciones Internacionales, Universidad de Comillas, Madrid, España; miembro del equipo docente del Máster de Paz, Seguridad y Defensa, Instituto Universitario General Gutiérrez Mellado (UNED), España, y del Máster de Políticas Públicas de Seguridad y Defensa de la Universidad Camilo Jose Cela. Correo electrónico: salda@rielcano.org
} 
este factor sea un importante obstáculo para los procesos de integración y de cooperación multilateral y, en consecuencia, para la proyección de la región como actor regional, en el ámbito de la seguridad y de la defensa. Sin embargo, considerando la importancia de combatir eficazmente el crimen organizado trasnacional, para América Latina sería trascendental convertirse en un actor regional, a través de los elementos señalados, ya que es la manera más efectiva de combatir esta amenaza.

Palabras clave: cooperación, crimen organizado, integración, seguridad internacional.

\title{
The challenges of Latin America to project as a regional actor in the field of international security
}

\begin{abstract}
This paper contemplates the possibility of Latin America to project itself as a regional actor in the field of international security. To achieve this objective, we have used a qualitative methodology to refer the following requirements: the subregional or regional integration process and the developing international multilateral cooperation in the field of security and defense, the participation of the Latin American countries in the international peace missions. In the evaluation of each of the products, the conception of a sovereignist perspective, by the nations of the region, is evident. Hence, in spite of the obvious progress achieved, this factor is a major obstacle to integration and multilateral cooperation processes and, consequently, to the projection of the region as a regional actor in the field of security and defense. However, considering the importance of effectively combating transnational organized crime, it would be crucial for Latin America to become a regional actor, through the elements mentioned, since it is the most effective way to combat this threat.
\end{abstract}

Keywords: Cooperation, organized crime, integration, international security.

\section{Os desafios da América Latina para projetar como ator regional no domínio da segurança internacional}

\section{Resumo}

Este artigo contempla a possibilidade da América Latina se projetar como ator regional no campo da segurança internacional. Para atingir esse objetivo, utilizou-se uma metodologia qualitativa para se referir aos seguintes requisitos: o 
processo de integração sub-regional ou regional e o desenvolvimento da cooperação multilateral e intra-internacional no campo da segurança e defesa e Participação de países latino-americanos em missões internacionais de paz. Na avaliação de cada um desses aspectos, a concepção de uma visão soberanista, pelos países da região, torna-se muito evidente. Assim, apesar do progresso obvio alcançado, este fator é um obstáculo importante para a integração e os processos de cooperação multilateral e, consequentemente, para a projeção da região como jogador regional na área da segurança e defesa. No entanto, considerando a importância de combater efetivamente a criminalidade organizada transnacional, seria crucial para a América Latina se tornar um ator regional, através dos elementos mencionados, uma vez que é a maneira mais eficaz de combater essa ameaça.

Palavras-chave: cooperação, o crime organizado, integração, segurança internacional.

\section{Introducción}

En un mundo globalizado, como el actual, la proyección internacional parece más trascendental a efectos no solo de influencia, sino también de seguridad, tanto internacional, como regional y nacional. Para hacer real esta posibilidad, en el caso de América Latina es imprescindible configurarse como un actor integrado, lo que a su vez exige la existencia de una cohesión interna y de una acción concertada basada, cuanto menos, en acuerdos mínimos, ante determinadas situaciones o coyunturas dadas o posibles.

En este trabajo, de tipo reflexivo, se ha aplicado una metodología cualitativa con el fin de contemplar las posibilidades de América Latina de proyectarse como un actor regional, en el ámbito de la seguridad y la defensa. Para ello la estructura del análisis se configura de acuerdo con los siguientes requisitos necesarios para alcanzar esta meta:

- Los avances de integración subregional o regional.

- El grado de desarrollo de la cooperación multilateral intra e internacional.

- El nivel de participación de los países latinoamericanos en las misiones internacionales de paz.

De la consideración de estos tres factores es posible comprobar que, por lo que respecta a la integración, en el ámbito de la seguridad y la defensa los avances han sido limitados, como también en los acuerdos de cooperación multilateral, en los cuales predominan los acuerdos de carácter binacional. En relación con las misiones de paz, aunque la región participa en estas 
misiones desde hace años, no ha sido muy destacada, a excepción del Cono Sur, cuyas fuerzas armadas han tenido mayor participación. En términos generales, las fuerzas de seguridad han estado históricamente volcadas en las necesidades internas de sus respectivos países; una tendencia que se ha acusado ante el escenario actual de inseguridad dominante, en mayor o menor medida, en toda la región.

Las razones fundamentales de este "ensimismamiento" hacia el interior son fundamentalmente dos, aunque no las únicas: un exacerbado nacionalismo y la debilidad estructural de los Estados latinoamericanos.

Esta debilidad estatal es una causa determinante del actual escenario de inseguridad, así como consecuencia de las medidas adoptadas. Si, por un lado, este factor ha favorecido la implantación del crimen organizado y la proliferación de la delincuencia común, por el otro, debido a la misma debilidad, la mayoría de los Gobiernos se ha estado desbordada por los altos niveles de violencia y la mayoría de ellos se ha visto obligada a recurrir a las Fuerzas Armadas (FAS, en adelante), además de la policía, para combatir estos altos niveles de criminalidad. Estas circunstancias han terminado por consolidar unas fuerzas de seguridad volcadas hacia el ámbito interno.

Asimismo, conviene tener presente que buena parte del problema de seguridad existente viene dada por el desarrollo de un crimen organizado transnacional que, sin embargo, no ha generado como respuesta gubernamental el desarrollo de una cooperación multilateral para combatirlo. Estos tratados podrían alimentar una dinámica muy beneficiosa para la región, no solo en términos de eficacia para combatir esta amenaza, sino también para recrear una conciencia e identidad subregional y regional, muy precaria aún, sin la cual no es posible la configuración de la región como un actor global. No obstante, la estrategia dominante, para combatir las amenazas transnacionales, continúa sometida a una visión nacional, una visión estratégica abocada al fracaso cuando se trata de este tipo de amenazas.

Valga mencionar, de acuerdo con los criterios de análisis adoptados, la existencia de factores de carácter estructural que obstaculizan la proyección de la región como actor global, en el ámbito de la seguridad y la defensa.

\section{Contexto de inseguridad: amenazas principales en América Latina}

En términos generales, desde el surgimiento de los Estado-nación latinoamericanos, la característica dominante en el ámbito de las relaciones intrarregionales ha sido la desconfianza y el aislamiento en relación con los vecinos (Gómez de la Torre, 2016 y Ramalho, 2016). Con respecto a las relaciones extraregionales, si últimamente se han diversificado mas (Tokatitlan, 2011), Estados Unidos ha sido el principal socio internacional para todos los países de la región. Esta es una relación sosteni- 
da y extraordinariamente complicada, donde la región, de manera simultánea o alterna, ha solicitado la atención de la gran potencia y criticado y desconfiado de sus pretensiones imperialistas.

En cualquier caso, es interesante señalar que las relaciones con Estados Unidos no han tenido lugar de manera conjunta, ni subregional. Cada país ha negociado de manera particular sus relaciones con los norteamericanos, al margen de sus vecinos. Este esquema se modifica con la caída del muro de Berlín y partir de los años 90, pues los proyectos de integración intensifican las relaciones interamericanas e internacionales. En la década de 2000, tiene lugar otro importante impulso con las propuestas del regionalismo posneoliberal; en esta etapa se enmarcaría la Unión Sudamericana de Naciones (Unasur) y la Comunidad de Estados Latinoamericanos y Caribeños (Celac). Sin embargo, el peso de una visión soberanista, entre otros factores, continúa limitando el desarrollo de estos proyectos (Alda, 2015a).

No obstante, pese a la inexistencia de una presencia internacional destacada, la región ha vivido con extraordinaria intensidad las amenazas internacionales existentes, tanto en la Guerra Fría, como en el actual mundo global. Durante aquel periodo, América Latina se convirtió en un espacio trascendental para el combate al comunismo. Aunque con muy diferentes intensidades, todos los Gobiernos de la región, mayoritariamente militares, se enfrentaron, en una guerra interna, a los movimientos revolucionarios que surgieron en cada país, con mayor o menor intensidad (Alda, 2013).

El fin del comunismo inaugura otro periodo que, en términos de seguridad, es también muy complejo, y en el cual las Ilamadas nuevas amenazas tienen una particular incidencia en la región, tanto que en la década de 2000 se ha ido convirtiendo en la región más violenta del mundo. Aunque el terrorismo internacional apenas tiene arraigo y presencia, sin duda el crimen organizado, ya sea local o internacional, se ha convertido en la principal amenaza.

Cabe destacar que en los dos periodos mencionados los conflictos interestatales han sido mínimos, mientras que los intraestatales han sido los dominantes. Sin embargo, se presentan características muy diferentes entre un periodo y otro, tanto por sus actores, como por sus motivaciones o por la forma como tienen lugar la conflictividad y la violencia.

\section{Una región de paz}

Frente a la historia bélica padecida en otras partes del mundo, por ejemplo, en Europa en el siglo XX, en el caso latinoamericano ha de señalarse la pacífica, si bien no idílica, convivencia vecinal. América Latina apenas ha sufrido conflictos bélicos a lo largo del siglo XX; los más recientes y más destacables serían la Guerra del fútbol entre Honduras y el Salvador, en 1969, que duró 6 días o la Guerra del Cenepa, entre Ecuador y Perú, en 1995, que se 
prolongó durante cinco semanas. Desde entonces no han tenido lugar más conflictos y, en este momento, las posibilidades de una guerra interestatal son aún menores que cuando tuvieron lugar las guerras mencionadas.

Esto no significa que la región no se encuentre exenta de tensiones, por motivos fronterizos o ideológicos; sin embargo, incluso en los momentos de mayor tensión ha sido posible recomponer las relaciones bilaterales, pese a los altibajos. De ahí que, pese a la división, lo trascendente sea resaltar la capacidad para resolver tensiones cíclicas u ocasionales, aunque ciertamente no llegan a resolver ni a limar el marcado nacionalismo que, en la mayoría de los casos, ocasionan dichas divisiones (Malamud, 2015).

\section{Conflictos intraestatales}

Mientras las posibilidades del ataque de un enemigo externo son remotas, los conflictos intraestatales han desbordado en buena parte de los Estados latinoamericanos. La región se enfrenta a una grave situación relacionada con los niveles de violencia e inseguridad generados por el crimen organizado y la delincuencia común, ambos asociados en muchas ocasiones.

El crimen organizado contempla un conjunto de actividades y tráficos ilegales, de los cuales el narcotráfico es el más importante y rentable de todos ellos. Este es un sustancioso negocio al que están asociados otros, como el trá- fico de personas, inmigrantes, prostitución, el tráfico de órganos, de armas, entre otras. De este mundo también procede, y en numerosas ocasiones relacionada directamente con el tráfico de drogas, una delincuencia pandillera que es capaz de tomar el control de importantes áreas, en el corazón mismo de las principales ciudades latinoamericanas. Si todas estas actividades se desarrollan al amparo del narcotráfico, no puede olvidarse el conjunto de delitos particularmente asociado a esta actividad, como el negocio de armas, el lavado de dinero y el comercio ilegal de precursores químicos.

El crimen organizado no siempre actúa con violencia, de hecho, no parece recomendable, pues llama la atención de las autoridades; no obstante, en América Latina, según los países, se ha manifestado con extrema violencia. En este sentido, son paradigmáticos los casos como el mexicano, el centroamericano, el brasileño o el colombiano. Por el contrario, en Bolivia, uno de los países que, pese al establecimiento de diferentes redes latinoamericanas y europeas, no se destaca por sus índices de violencia (Campero, 2012), aunque podría estar convirtiéndose en el epicentro de la droga de la región (McDermott, 2012).

La región concentra casi el 9\% de la población mundial, pero padece más del $30 \%$ de los homicidios. La referencia con otras realidades, como los países nórdicos, ayuda a dimensionar la gravedad del problema de la delincuencia, como ilustra la figura 1. 


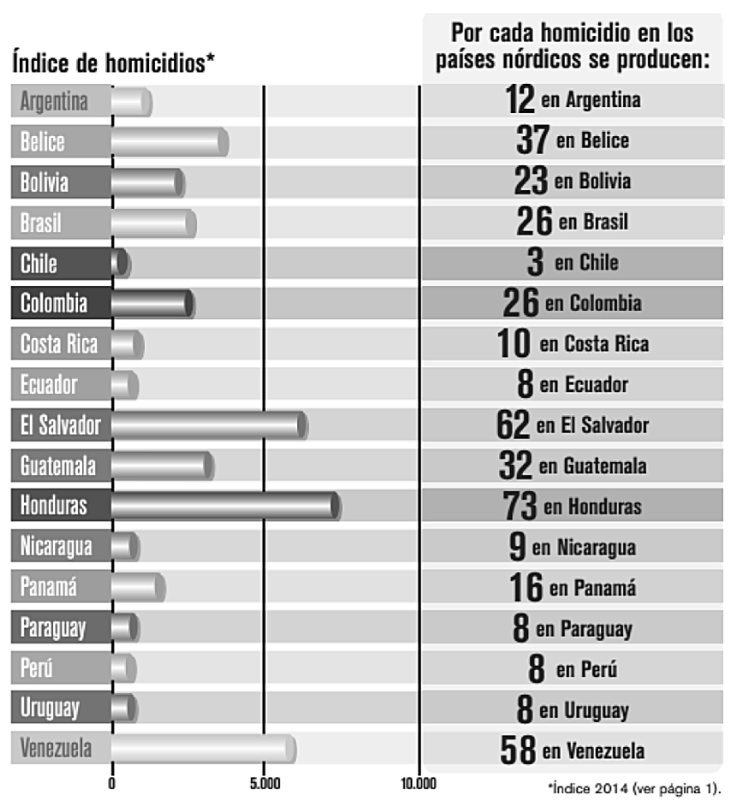

Figura 1. Índice de homicidios en América Latina y países nórdicos

Fuente: Resdal (2016a).

Como se aprecia en la figura 1, pese 100.000 habitantes, por subregiones, a los altos índices de violencia, en general, esta no afecta por igual a todos los países. Si seguimos tomando como referencia los homicidios por cada aún más (figura 2).

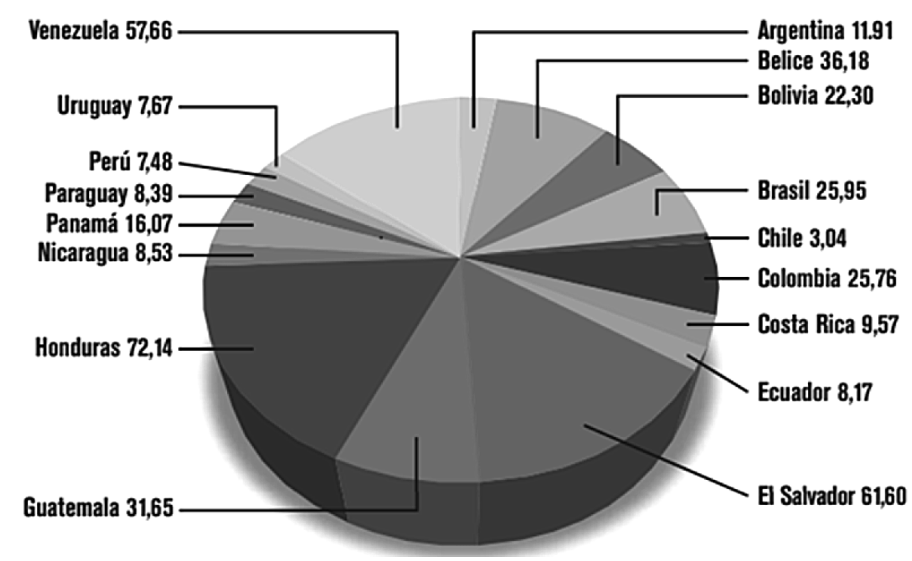

Figura 2. Número de homicidios por cada 100.000 habitantes

Fuente: Resdal (2016a). 
Una buena referencia para considerar la dimensión del problema es contemplar el número de países que superan los 20 homicidios por cada 100.000 habitantes, ya que Naciones Unidas considera que este número de homicidios indica un grave problema de violencia criminal. Tomando esta refe- rencia, es posible comprobar que hay varios países que superan esa cifra y aquellos que no la alcanzan, en cualquier caso, mantienen tasas muy altas. No obstante, los actos de delincuencia más comunes son los robos, o al menos en Sudamérica, si se comparan con los homicidios, como se ve en la figura 3.

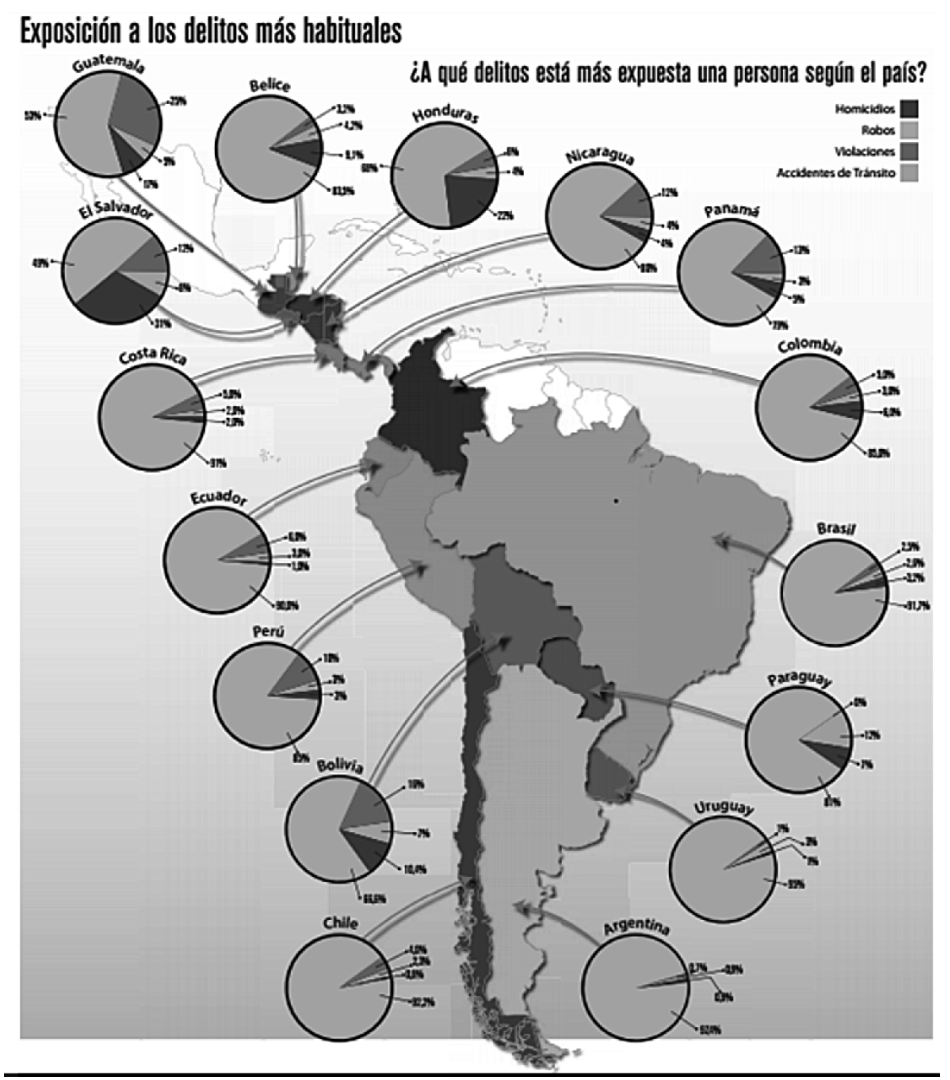

Figura 3. Delitos más comunes en América Latina

Fuente: Resdal (2016a).

La expansión internacional de las redes criminales latinoamericanas

Toda esta violencia delictiva se ha visto incrementada en la región por el proceso de expansión de redes criminales. Las redes colombianas y mexicanas son las que han protagonizado un mayor proceso expansivo, orientado hacia los mercados sudamericanos 
y europeos, y con esto han adoptado una naturaleza transnacional. Este proceso se ha visto favorecido por varios factores como el crecimiento de la demanda sudamericana, la presión ejercida por las políticas de mano dura y la debilidad estatal.

En relación con la producción, además de Colombia, la cocaína producida en Perú y Bolivia cada vez más se orienta hacia los mercados de consumo sudamericanos y europeos, como el brasileño, el uruguayo o el argentino, y también los europeos, como el español. Venezuela, Brasil, Uruguay o Argentina son plataformas fundamentales de distribución para llegar a Europa. En el Caribe, que al parecer está tomando de nuevo cierta relevancia, Jamaica y República Dominicana también son puntos de salida (Alda, en prensa).

La articulación de estas rutas ha sido posible mediante la configuración de redes criminales como auténticas multinacionales con presencia en todo mundo. A través de múltiples alianzas, con grupos o individuos, el cartel de Sinaloa no solo tiene presencia en toda América Latina y Europa, sino también en China (Logan, 2013, Pachico, 2012). La misma expansión internacional también ha sido llevada a cabo por organizaciones criminales colombianas, como Los Urabeños o las Bacrim colombianas, presentes en toda América Latina y en Europa (Gagne, 2016).

La cooperación no solo se da entre redes latinoamericanas (Semana, 2016), sino además entre estas y otras estructuras como la mafia italiana (Council on Hemispheric Affairs, 2013) o con estructuras criminales de Los Balcanes (European Monitoring Centre for Drugs and Drug Addiction [EMCDDA], 2016) (Yagoub, 2016), por ejemplo. Tampoco dicha colaboración tiene lugar en el ámbito del mercado de la cocaína; no hay que olvidar que estas estructuras realizan diferentes actividades criminales. La descripción hecha por Eduardo Buscaglia (2014) respecto a lo que ocurre en Argentina ilustra muy bien la estructura y modus operandi de estas organizaciones transnacionales:
No es solo el narcotráfico. Se trata de franquicias de grupos criminales que se han asentado en Argentina, tanto grupos asiáticos, con base en Guandong, China, como grupos la- tinoamericanos con base patrimo- nial en México, así como otros de El Líbano, que operan con impunidad en Argentina y se dedican al narco- tráfico y a la trata de personas, al tráfico de armas, al tráfico ilegal de explotación minera, al contrabando de flora y fauna y al establecimiento de bases patrimoniales comprando tierras $[\ldots]^{\prime \prime}$.

El alcance y la proyección de estas redes ponen de manifiesto que el escenario de inseguridad latinoamericano está determinado en buena parte por redes criminales transnacionales, lo que exige que su combate se realice en los mismos términos. La cooperación intrarregional e internacional es absolutamente imprescindible. Esta- 
dos Unidos con México, Centroamérica y Colombia ha desarrollado formas de cooperación. Con la Unión Europea la situación es más precaria y la cooperación es solo incipiente. Si este plano de cooperación es muy limitado, el regional no es muy diferente.

El principal problema es que las amenazas transnacionales se continúan enfrentando en términos nacionales, al margen del vecino o países vecinos, aunque todos se encuentren atrapados en una malla de redes criminales que constriñe a toda la región y que alcanza a Estados Unidos y Europa.

\section{Causas que no favorecen la proyección internacional de la región en el ámbito de la seguridad}

De acuerdo con este escenario de inseguridad descrito, conviene contemplar factores que expliquen las causas que favorecen el nivel de implantación del crimen organizado y su expansión, ya que este análisis proporciona muchas claves para explicar la escasa proyección internacional en el ámbito de la seguridad de la región y de buena parte de sus países integrantes.

La debilidad estatal es un elemento trascendental que atraviesa todo el problema, tanto en su origen, como en la forma de enfrentarlo. Si por un lado la debilidad estatal favorece la particular implantación del crimen organizado, por el otro, la misma debilidad induce a los Gobiernos a implicar a las fuerzas armadas en el enfrentamiento esta amenaza, puesto que los cuerpos policiales se encuentran desbordados. Las "tareas policiales" desempeñadas por las fuerzas militares se suman a otros roles que ya llevan realizando en territorio nacional, como las relacionadas con el desarrollo nacional que han acabado por sobrecargar de misiones a estas instituciones y que necesariamente limitan las posibilidades de participar en misiones de paz.

A la debilidad estatal es preciso sumar el tipo de políticas de seguridad empleadas para intentar controlar esta criminalidad. El carácter fundamentalmente represivo de las estas no ha logrado resolver el problema de seguridad, pero en muchos casos incluso ha generado el efecto contrario.

\section{La debilidad de los Estados en América Latina: espacios idóneos para la implantación del crimen organizado}

La existencia de Estados incapaces de imponer el imperio de la ley, en todo el territorio y para todos sus ciudadanos, hace de sus respectivos espacios nacionales un campo abonado para la implantación de redes criminales (Alda, 2015b). La posibilidad de que determinadas personas o territorios queden eximidos del cumplimiento de la ley tiene lugar cuando la corrupción es sistémica (Lupsha, 2002; Geffray, 2011). En estos casos, cabe la posibilidad de sobornar a un representante del Estado, con el fin de contar con su com- 
plicidad e incluso participación para llevar a cabo actividades ilegales. Esta realidad es la que explica la particular implantación del crimen organizado y se cumple en buena parte de los Estados latinoamericanos (Alda, 2016).

La coexistencia de un orden formal e informal es el mejor escenario posible para el crimen organizado, ya que, por un lado, disfruta de autonomía al margen del Estado y, por otro, puede obtener su apoyo, y ganarse así el favor de sus representantes. Sin embargo, aunque llegue a sustituir al Estado en determinados territorios, no puede prescindir de él. En realidad, lo que necesita es contar con su apoyo y esta posibilidad está garantizada mediante el orden informal, a través de la corrupción. Por último, la capacidad de regulación y orden del que es capaz este Estado, puesto que no es fallido, es imprescindible para garantizar la estabilidad política, económica y financiera, así como la infraestructura necesaria para el desarrollo de sus actividades ilícitas (Alda, 2016a).

De ello se desprende que un Estado débil puede ser mucho más atractivo para el crimen organizado que uno fallido (Rice y Stewart, 2008). En el primero, tiene la suficiente capacidad para garantizar su protección, aunque esta protección al crimen hace imposible la del ciudadano, mientras que en el segundo, en la medida que la anomia es mayor, ante el menor cumplimiento de la legalidad y mayor ineficacia del orden formal, no siempre está asegurada la protección ni para el crimen organizado, ni para la ciudadanía (Alda, 2015b).

Esta complicidad con agentes privados y públicos es la que alimenta la fortaleza de estas redes criminales y las que hacen posible su proyección internacional. Colombia, Perú y Bolivia no solo son países exportadores por las óptimas condiciones climáticas y geográficas que reúnen para el cultivo de hoja de coca, también lo son porque, además, la debilidad estatal proporciona esta posibilidad. Pero no solo eso, dicha debilidad favorece la proliferación de laboratorios artesanales para el procesamiento de pasta base de cocaína, en diferentes países de la región, y facilita el movimiento de cocaína, por toda la región, tanto para abastecer los nuevos mercados intrarregionales, como para trasladar la cocaína a los puertos o aeropuertos que transportaran la mercancía hasta Europa. Las posibilidades de organizar todo este tráfico, su producción, procesamiento y distribución, se ve favorecida por la falta de representantes estatales o por la complicidad de estos.

\section{Fuerzas de seguridad sobrecargadas y volcadas en el ámbito interno}

La debilidad estatal también influye en el tipo de fuerzas de seguridad que caracteriza, en términos generales, a la región, a excepción del Cono Sur. Estas fuerzas de seguridad tanto de policía, como FAS, están configuradas fundamentalmente para la seguridad interior. 
La mayoría de los Estados latinoamericanos, en mayor o menor medida, no tienen presencia en todo el territorio nacional y las FAS son la única institución capaz de llegar a regiones de difícil acceso y atender necesidades básicas de la población; en la mayoría de los países de la región son las únicos que garantizan, cuando no la hay, la presencia del Estado.

Con las transiciones democráticas, países como Argentina, Chile y Uruguay expresaron en sus respectivas constituciones que las FAS tendrían como principal misión la defensa ante un enemigo externo. No por casualidad estos países, donde se establece una clara separación entre seguridad interior y exterior, son los que han tenido una mayor participación en misiones de paz.

Sin embargo, en el resto de la región, las FAS continuaron desempeñando misiones que ya realizaban en el pasado, en territorio nacional, y además se han ido agregando otras nuevas, de acuerdo con las necesidades de unos Estados que carecen de la solidez institucional necesaria para ir resolviéndolas, a través de las instituciones correspondientes. Esto explica la acumulación de misiones que no siempre corresponden a las fuerzas de seguridad y muy particularmente a las FAS que, ante una mayor institucionalidad, son capaces de llevar a cabo multitud de misiones.

La mayoría de las FAS latinoamericanas, en términos generales, en los textos constitucionales, se mantienen como garantes del orden constitucional, fuerza de protección ante un enemigo externo y agentes del desarrollo nacional (Sepúlveda y Alda, 2008). Esta misión abarca innumerables tareas relacionadas con las obras públicas, campañas de sanidad o de alfabetización. Con respecto a esta misión, cabe hacer especial mención al caso venezolano y boliviano, ya que la asignación de innumerables tareas, en este ámbito, incluso de carácter productivo y administrativo, las han proporcionado espacios de gestión que superen el ámbito militar, lo que favorece la militarización de políticas sociales y económicas (Alda, 2008a).

A estas misiones tradicionales se ha agregado el apoyo ante desastres naturales que, como puede apreciarse en la figura 4, se ha asignado a las FAS de manera generalizada en toda la región.

Dada la riqueza de la región en recursos naturales, y de acuerdo con el valor estratégico otorgado a estos, también las FAS se han incorporado al cuidado del medio ambiente y a la protección de los recursos naturales, en los últimos años (ver figura 5).

A estas misiones es preciso agregar la participación de las FAS en la seguridad pública, combatiendo, junto a la policía, la lucha contra el contrabando y el crimen organizado, mediante la persecución de sus diferentes tráficos, como el de la cocaína, la tala o la minería ilegal. También han de agregarse 


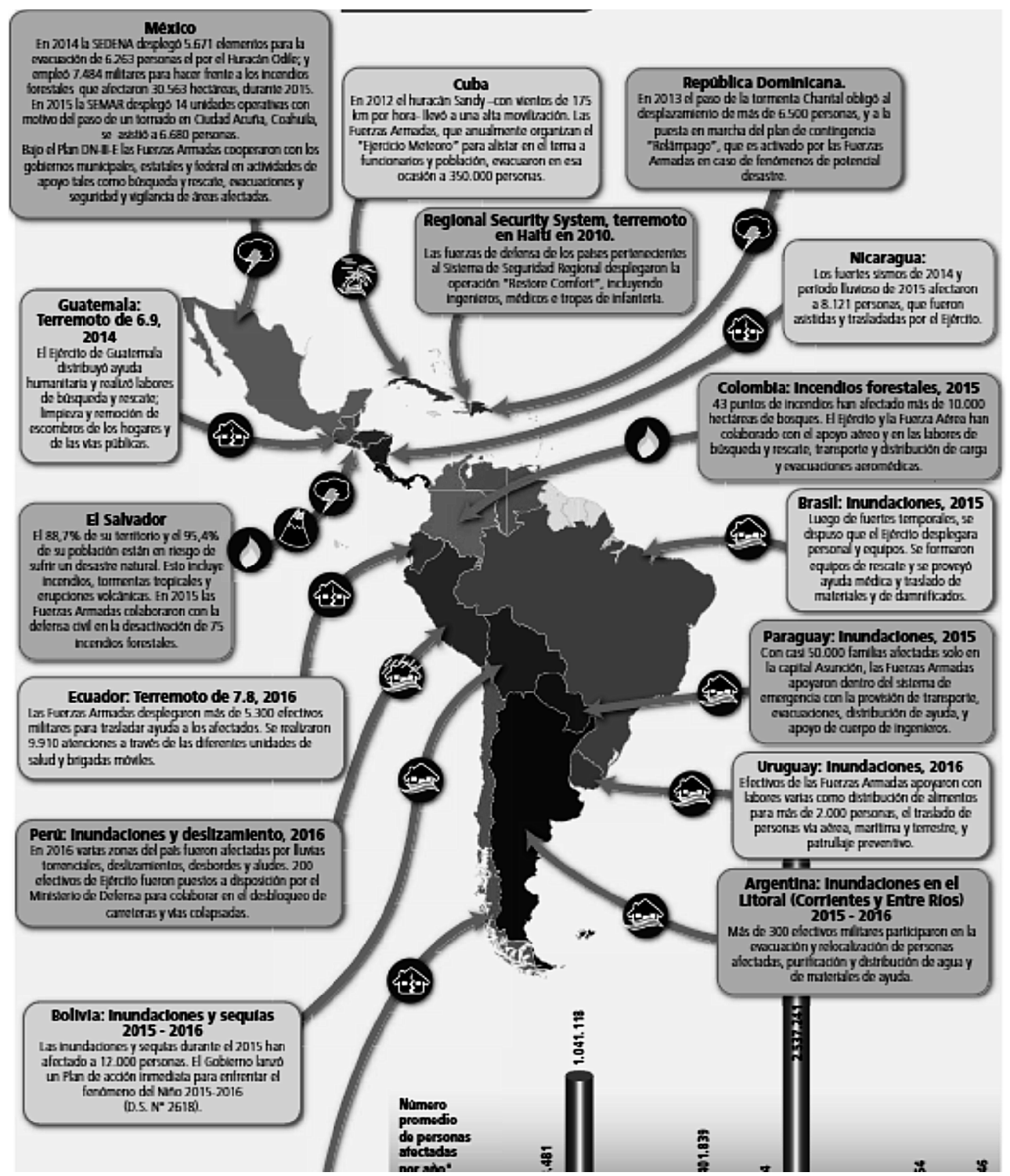

Figura 4. Apoyo de las fuerzas armadas ante desastres naturales

Fuente: Resdal (2016b, p. 73). 


\section{Protección de recursos naturales}

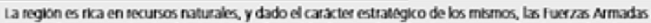

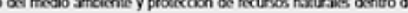
obptives estrateglos.

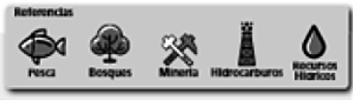

Principales rocursos / Pals
28 0 Argentina

28 $\quad$ Bolivia

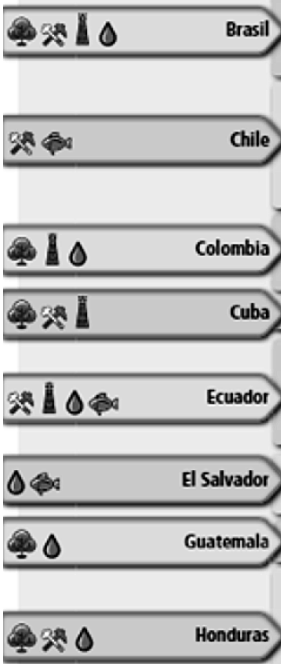

010

$920 \quad$ Paraguay

28

Pert

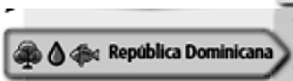

Uruguay 0

1 1 Venezuela

Venezuela

\section{Programas / actividades principales}

"Senvio de Segundad Ambienta" de la Armach, para contribur con la poluca ambientai nacional.

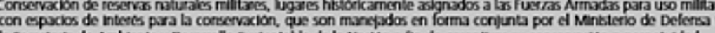

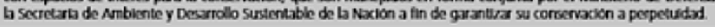

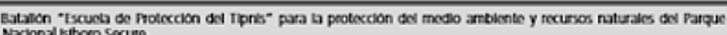

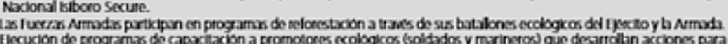
tacuelon de programas de capacitax

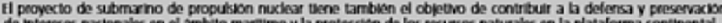
de intereses naxbonales en el ambito martimo y la proteccion de los feccussos naturales en la plataforma continental. Solema de Geston Amavonta Arit vigkancia, control y protection de la costa brasliena preve la gestion de to

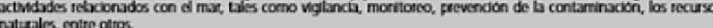
natuales, entre otros.

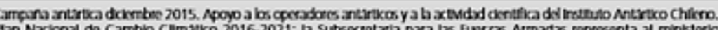

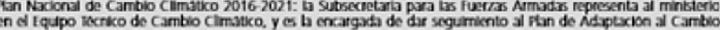

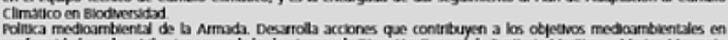

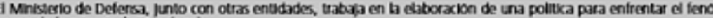

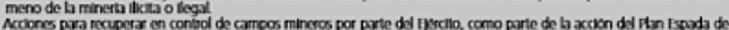

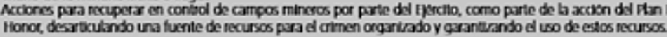

Delersa cul: la cobrervacion y el contral de la contaminacion, quimica, radoactiva y biologica

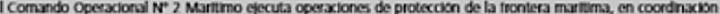

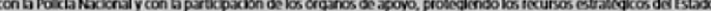

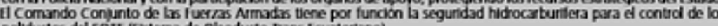

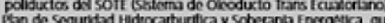
gerven axciones para dar soporte a la manutención y

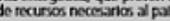

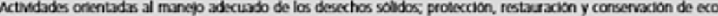
Accones de retotestacion y limpiera de Lagos desarolladas por la fucrra Amadz

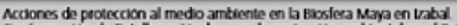
Contormacion de tataliones vendes para la protecion aribicntal en el peten.

Apoyo de las fueras Nmadas en Fan Naconal para ta conservacion del Laguar

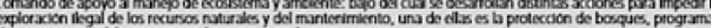
de conservación del exosstema y las campanas de retorestación

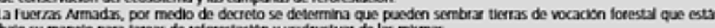
bapo su mancop para taness de teforestacion y usulnutuar de las mismax

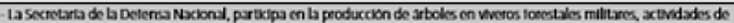

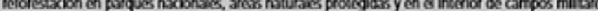

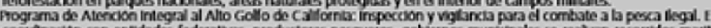

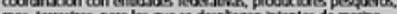

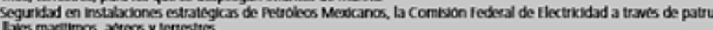

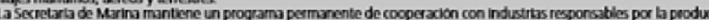

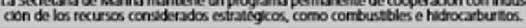

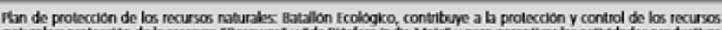

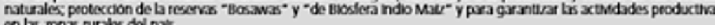

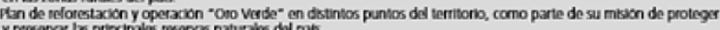

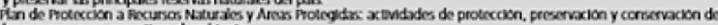
bs recursos para grantitar d anbiente.

Win de abotiracon de los fuecras Nmadx

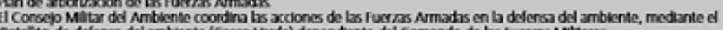

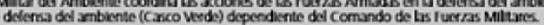

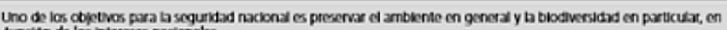

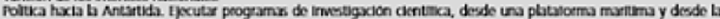

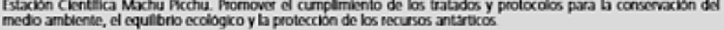

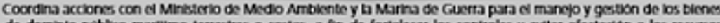

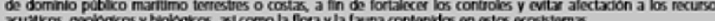

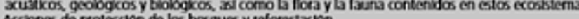

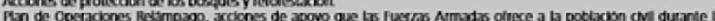

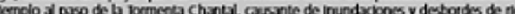
provocado por fustes aguareros.

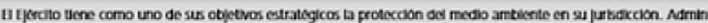

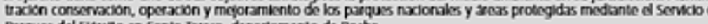
Parques del fyection en Santa levera, departamento de koch

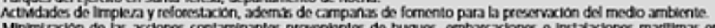
is aguar, asi coeno neutraluat los electos adversos de incidentes de contaminadion marina que puedan peoducisse.

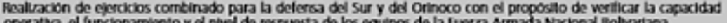

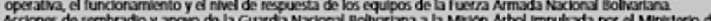
Poder popular para ed Nmbiconte.

Figura 5. Participación de las fuerzas armadas en la protección al medio ambiente

Fuente: Resdal (2016b, pp. 79 y 80). 
las tareas relacionadas directamente con la seguridad ciudadana, basado en el patrullaje y presencia en las calles, junto a la policía, o la custodia de cárceles (Alda, 2012a).

En México y Centroamérica, las FAS se encuentran inmersas en todas las misiones citadas; la región andina tampoco es ninguna excepción. Las instituciones militares en Ecuador, Venezuela y Bolivia desempeñan igualmente estas misiones, a excepción de Perú y Colombia. En este caso, las FAS no intervienen en seguridad ciudadana, pero en ambos países ambos ejércitos continúan combatiendo movimientos guerrilleros; por ejemplo, en Perú a una guerrilla debilitada que se mantiene en el Valle de los ríos Apurímac, Ene y Mantaro (VRAEM), heredera del movimiento de Sendero Luminoso. En Colombia, después de un conflicto interno de más de cincuenta años, tras la firma de la paz en 2016, las FAS se encuentran inmersas en el proceso de desmovilización de la guerrilla.

Respecto al Cono Sur y a Brasil, habría que señalar diferencias, ya que en este último caso las FAS habrían participado en el ámbito de la seguridad interior. No obstante, lo cierto es que podría afirmarse una tendencia dominante basada en la dedicación de estas a misiones de defensa exterior, sin implicación en la seguridad interior. De hecho, esto en buen parte explica que las FAS de estos países tengan una muy particular dedicación a las misiones internacionales, con bastante distancia respecto al resto de la región.
Brasil es un caso un tanto particular, sus FAS se han implicado en el combate al crimen en favelas de las ciudades más importantes del país, desde mediados de los noventa. Bajo las presidencias de Luis Ignacio Lula Da Silva y Dilma Roussef se intentó restringir la participación militar en seguridad interior (Kalil, s. f.) potenciando a la policía, pero esto no ha significado seguir utilizando, excepcionalmente, a las FAS en este ámbito, por razones de seguridad nacional.

El caso más representativo es el argentino: todas las disposiciones legales separan tajantemente las tareas de seguridad interior de la defensa externa y esta última se circunscribe a las FAS. No obstante, podría iniciarse una reorientación bajo la presidencia de Mauricio Macri, desde la cual se ha planteado una mayor implicación de las FAS para combatir el crimen organizado. Sin embargo, está por concretarse cuál sería la participación militar, y todo indica que quedaría limitado a apoyo logístico (Dinatale, 2016).

Chile y Uruguay se encontrarían enmarcados dentro de esta tendencia. Sus FAS no desempeñan misiones de carácter interior, pero se contempla la posibilidad de realizar tareas de apoyo en situaciones de desastres naturales, como sucedió en el terremoto de 2010, en Chile (Bartolomé, 2009).

En el mapa de la figura 6 puede apreciarse esta implicación militar en el desempeño de tareas vinculadas con la seguridad pública, en la región, que 
irían, según los países, desde la seguridad ciudadana hasta el combate del crimen organizado, custodia de centros penitenciarios o fronteras.

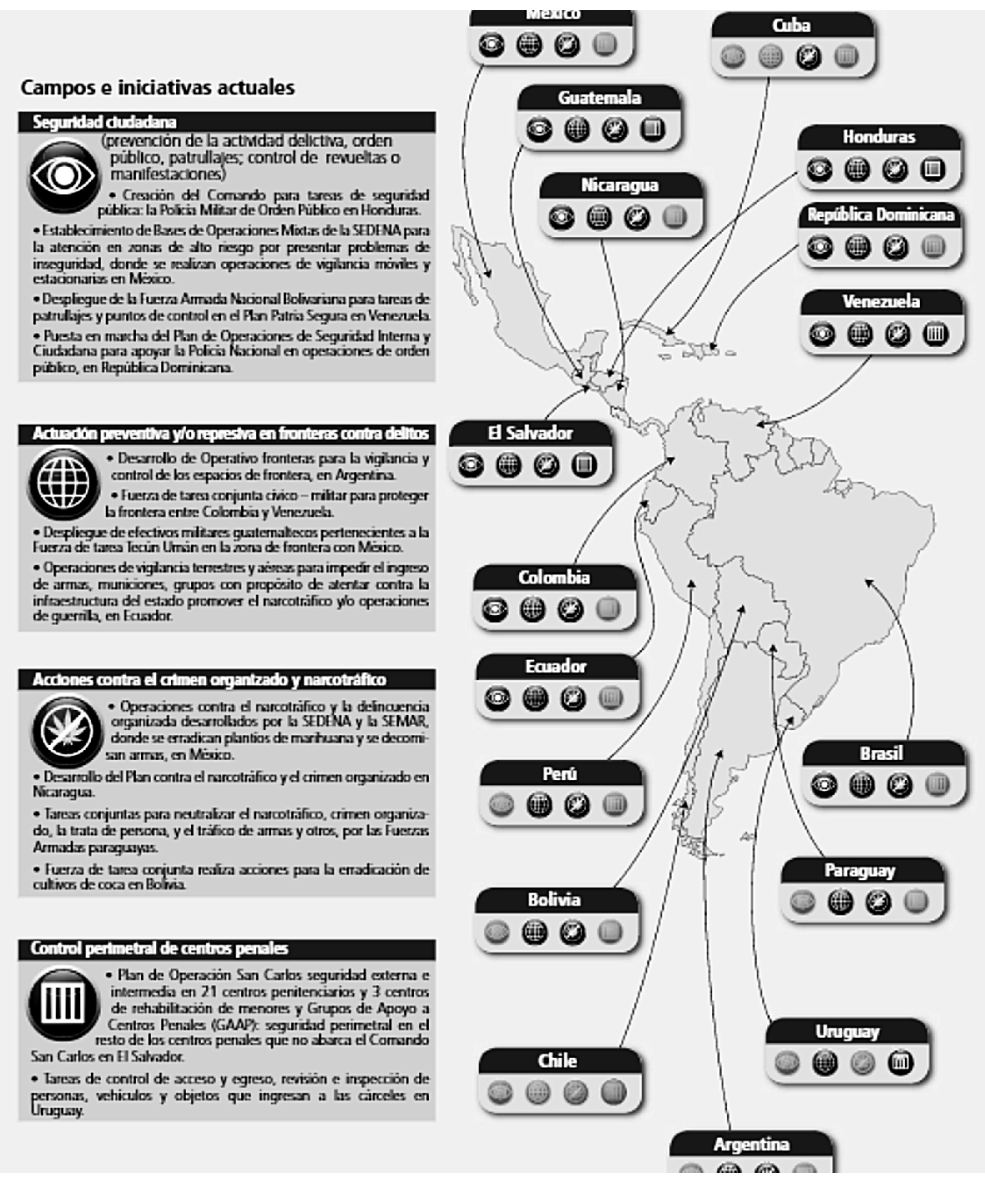

Figura 6. Misiones de las fuerzas armadas en seguridad interior y ciudadana

Fuente: Resdal (2016b, p. 74).

Esta acumulación de misiones, sin duda, tiene multitud de implicaciones que afectan a muy diferentes ámbitos que van desde las relaciones civiles militares, hasta la eficiencia de la corporación militar al tener que atender tantas misiones y tan dispares. Esto sin contar con la desprofesionalización que lleva consigo el desempeño de todas ellas para una institución creada y estructurada para la defensa exterior (Alda, 2012a). Pero más allá de estas cuestiones, y en relación con las misiones internacionales, este nivel de dedicación en el ámbito de la seguridad interna hace, cuanto menos, difícil la plena dedicación militar a las misiones de paz. 


\section{Políticas de seguridad nacionales y el "efecto cucaracha"}

La dedicación de todas las fuerzas de seguridad, policía y fuerzas armadas, al combate de las amenazas que afectan al espacio intraestatal no ha mejorado la situación. Estas fuerzas de seguridad han sido enmarcadas dentro de políticas públicas de seguridad, de carácter fundamentalmente represivo, políticas que han sido consideradas como un fracaso, como muestra la Comisión Global de Política de Drogas (2011), desde su primer informe.

La persecución reactiva ejercida mediante estas políticas a las estructuras criminales en países como México o Colombia generó su dispersión por el resto de la región, en un momento cuando la demanda de cocaína comenzó a crecer en los países vecinos, lo que no ha hecho más que complicar el escenario de inseguridad regional. En otras palabras, la fragmentación del mundo criminal y la búsqueda de espacios de refugio y de mercados, para evitar la presión ejercida por las autoridades, son los efectos principales generados por estas políticas (Garzón, 2013). Bagley (2012) lo ha calificado como "efecto cucaracha": las organizaciones criminales, para evitar la detección después de que la luz ha sido encendida sobre ellas, se han desplazado de un municipio a otro, de un país a otro, en búsqueda de lugares más seguros y autoridades estatales más débiles.

El "efecto cucaracha" se genera por la presión represora de las autorida- des y es posible por la visión estratégica aplicada de manera particular por cada país. En la medida en que no hay estrategias transnacionales coordinadas entre Estados, estas políticas "nacionales" desplazan las redes, pero no logran controlarlas. Lo más preocupante es que, por el momento, no hay perspectivas de mayor concreción en cooperación intrarregional, ni internacional para el combate de amenazas transnacionales, tampoco se atisba un cambio de políticas. De manera que todo indica que continuarán predominando las políticas de "mano dura" con la participación de las fuerzas armadas.

\section{La participación de América Latina en la seguridad internacional}

El desempeño de todas las misiones descritas no deja de recrear la idea de unas FAS cuya justificación está basada no en su proyección internacional, sino en su dedicación a los problemas y a las necesidades internas, de muy diferente naturaleza. Se reproduce de manera permanente, por parte de toda la sociedad, la asociación de FAS y de las fuerzas de seguridad a la resolución de multitud de problemas "nacionales"; imagen que no deja de poner de manifiesto la dedicación a cuestiones nacionales y no internacionales de las fuerzas de seguridad latinoamericanas.

La tabla 1 expone el número de efectivos que componen las FAS de cada uno de los países latinoamericanos y el número de efectivos que son enviados a misiones de paz. 
Tabla 1. Efectivos en misiones de paz en 2016

\begin{tabular}{|l|c|c|}
\hline \multicolumn{1}{|c|}{ País } & Total FAS & $\begin{array}{c}\text { Efectivos } \\
\text { misiones de paz }\end{array}$ \\
\hline Argentina & 79.845 & 380 \\
\hline Bolivia & 34.078 & 47 \\
\hline Brasil & 366.614 & 1.288 \\
\hline Chile & 67.683 & 451 \\
\hline Colombia & 265.050 & 1 \\
\hline Ecuador & 41.403 & 6 \\
\hline El Salvador & 24.023 & 231 \\
\hline Guatemala & 180.181 & 238 \\
\hline Honduras & 15.216 & 72 \\
\hline México & 267.656 & 30 \\
\hline Paraguay & 16.087 & 158 \\
\hline Perú & 78.296 & 371 \\
\hline $\begin{array}{l}\text { República } \\
\text { Dominicana }\end{array}$ & 58.281 & 12 \\
\hline Uruguay & 22.316 & 1.423 \\
\hline
\end{tabular}

Fuente: Resdal (2016b, p. 44) y Naciones Unidas (s. f.)

Si la comparación entre ambos datos revela el escaso número de efectivos dedicados a las misiones de paz, el porcentaje entre ambas cifras todavía es más significativo (tabla 4).

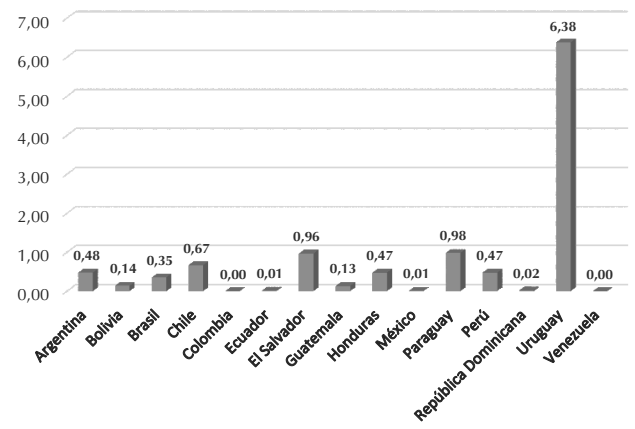

Figura 7. Porcentaje de efectivos militares que aporta cada país a misiones de paz de las Naciones Unidas

Fuente: elaboración propia, a partir de Resdal (2016b, p. 44) y Naciones Unidas (s. f.).
Ningún país, incluso aquellos que aportan más efectivos a las misiones de paz, a excepción de Uruguay, alcanza el $1 \%$ del total de sus fuerzas armadas. En la tabla 1, los datos solo hacen referencia a 2016, pero no dejan de ser significativos. Uruguay, a gran distancia del resto, es el país que más efectivos aporta a las misiones de paz de la ONU (González, 2014); le siguen Chile y Argentina, que de manera pionera y sostenida, en la región, han participado en misiones internacionales. En el caso de Argentina, desde principios de los años 90 y en Chile desde finales de esa misma década (Lafferriere y Soprano, 2016; Le Dantec, 2006; Perry, 2009). Paraguay, cuyo marco legal limita la participación en determinadas misiones de las FAS, en suelo nacional, desde principios de la década de 2000 participa en este tipo de misiones.

Es particularmente significativo el caso brasileño. Pese a ser un aspirante como líder internacional, no deja de llamar la atención el hecho de que su participación en misiones de paz no sea particularmente importante, de acuerdo con los datos de 2016. No obstante, esta afirmación exige ser matizada, ya que Brasil ciertamente ha procurado dar importancia a su aportación a la seguridad internacional, como forma de confirmar su liderazgo como potencia; así lo demuestra la iniciativa que dirigió en relación con la Misión de Estabilización de Naciones Unidas, en Haití (Misión de Estabilización de las Naciones Unidas en Haití [Minustah]) (Suárez, 2005). Sin embargo, en términos generales, nuevamente habría que 
remitir a un modelo de fuerzas armadas, en el caso brasileño, más volcadas en el ámbito interno que sus vecinos del Cono Sur, pese a sus aspiraciones internacionales, lo que no deja de ser contradictorio.

En el caso centroamericano, en particular El Salvador y Honduras, realizan un extraordinario esfuerzo, ya que el índice de inseguridad de estos países es muy alto y sus FAS también están volcadas en el desempeño de numerosas misiones en el ámbito interno. Sin duda, su participación en la fuerza multinacional que lideró España, en Irak, marca un hito en su participación posterior en misiones de paz.

Teniendo en cuenta esta visión predominantemente "nacionalista" de la seguridad, se explica que la seguridad internacional no se contemple como una cuestión prioritaria, aunque ese problema, en última instancia, afecte directamente a la región. En consecuencia, puede entenderse que la aportación, en el prorrateo de cuotas, a Naciones Unidas como región sea del $8 \%$.

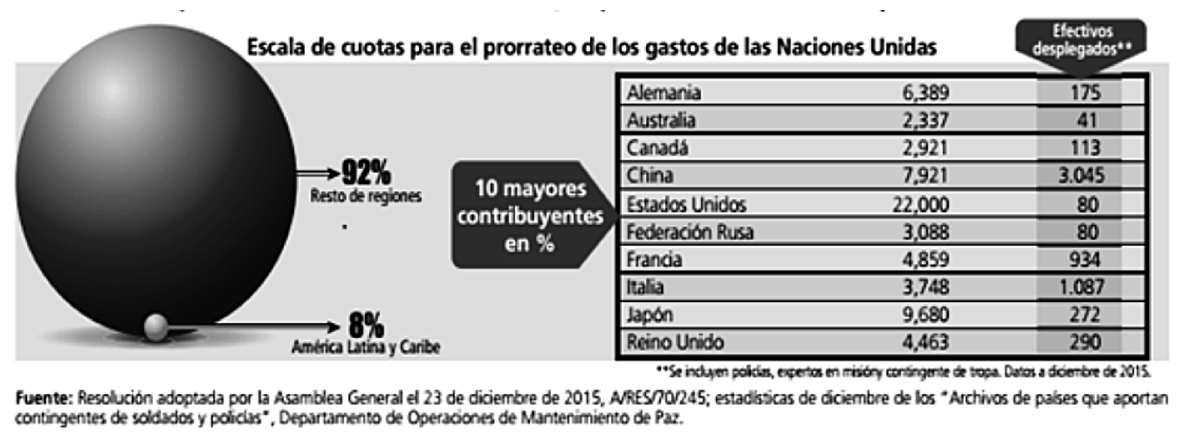

Figura 8. Escala de cuotas para el prorrateo de los gastos de Naciones Unidas

Fuente: Resdal (2016b, p. 65).

Esta limitada aportación podría explicarse por los gastos que acarrearía a los Estados el hecho de contribuir con efectivos a las misiones de paz; sin embargo, solo es posible en parte. América Latina está ya integrada mayoritariamente por países de renta media, no pobres; pero más allá de la disponibilidad de los recursos, parece que la prioridad de una visión nacionalista necesariamente relativiza la importancia de la seguridad internacional, pese a vivir en un mundo globalizado.
De hecho, la participación en misiones de paz, cuando es voluntaria, es remunerada por Naciones Unidas y este factor, a excepción del caso de Uruguay, no ha sido suficiente aliciente para que la aportación de efectivos a las misiones de paz, por parte de los países de la región, haya sido mayor.

La figura 9 proporciona una visión comparada, con respecto a otras regiones, sobre la participación de América Latina en misiones de paz: 


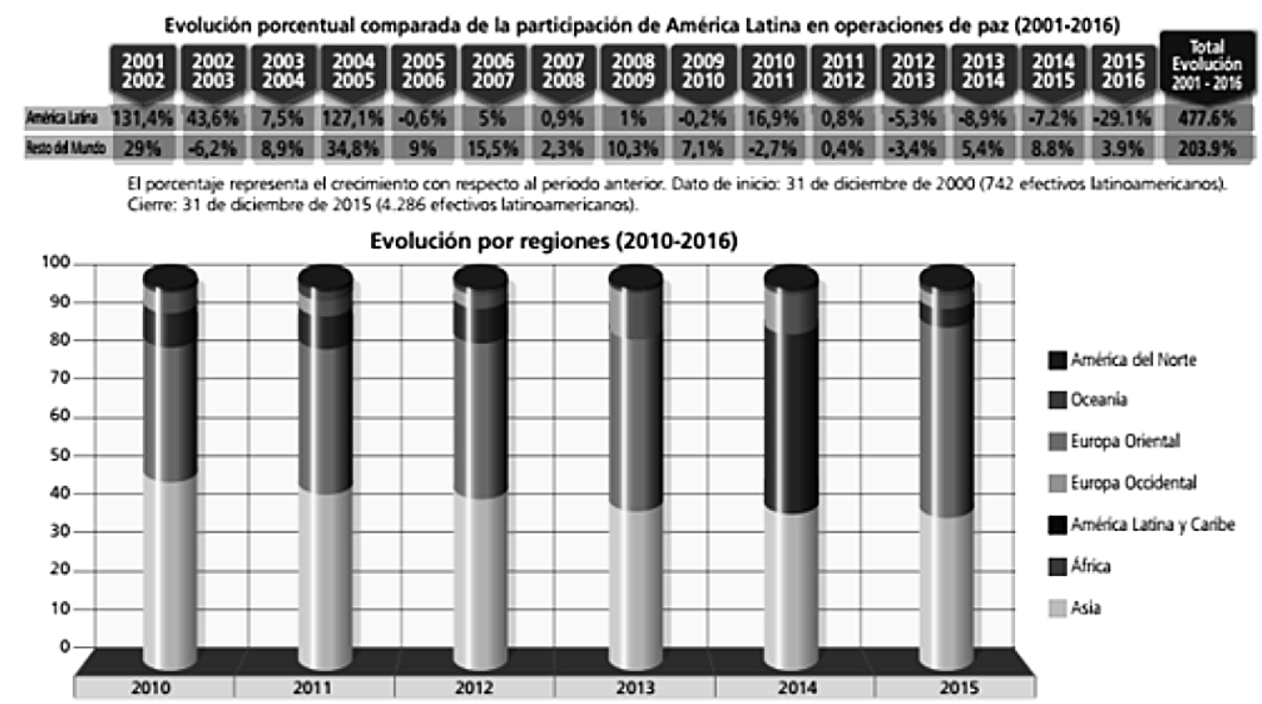

Fuente: Elaboracion propia en base a la informacion suministada por la pagina web del Departameno de Operaciones de Mamenimiento de Paz de las Naciones Unidas, estadlaticas de diciember de los "Archivo de pabes que aportan contingentes de soldados y policiss", para los afos correspondientes. Para el caso de 2016 se consideran las estadisticas de junio.

Figura 9. Evolución porcentual comparada de la participación de América Latina en operaciones de paz (2001-2016)

Fuente: Resdal (2016b, p. 64).

Los datos de la figura 10 aportan otra información de utilidad y ponen de manifiesto que a pesar de las limitaciones en la participación en las misiones de paz, no puede negarse que esta ha ido en aumento en los últimos años. El mapa de la figura 7 permite comprobar que además la región no se ha limitado a participar en misiones del entorno regional, como en Haití, sino que también hay militares latinoamericanos en muy diferentes partes del mundo.

Ambos datos demuestran el intento sostenido de la región, o al menos de algunos de sus países, para asegurarse una presencia internacional a través de las misiones de paz. Sin duda, Minustah marca un hito trascendental en este cambio de posición en relación con la seguridad internacional. Dicha misión ha sido dirigida por la región y con una participación mayoritaria de países latinoamericanos; además, la experiencia ha animado a estos países a estar en otras partes del mundo y estar presentes en África o en Líbano (Radio ONU, 2015). En definitiva, cabe decir que a pesar de que la participación es limitada, no significa que no haya aumentado, ni que se haya diversificado (Benítez, 2008).

En este sentido, cabe enfatizar en el planteamiento expuesto, como tendencia general. Los países que han dedicado sus FAS a misiones internas, a diferencia de los países del Cono Sur, no han tenido una particular proyección internacional en misiones de paz. 


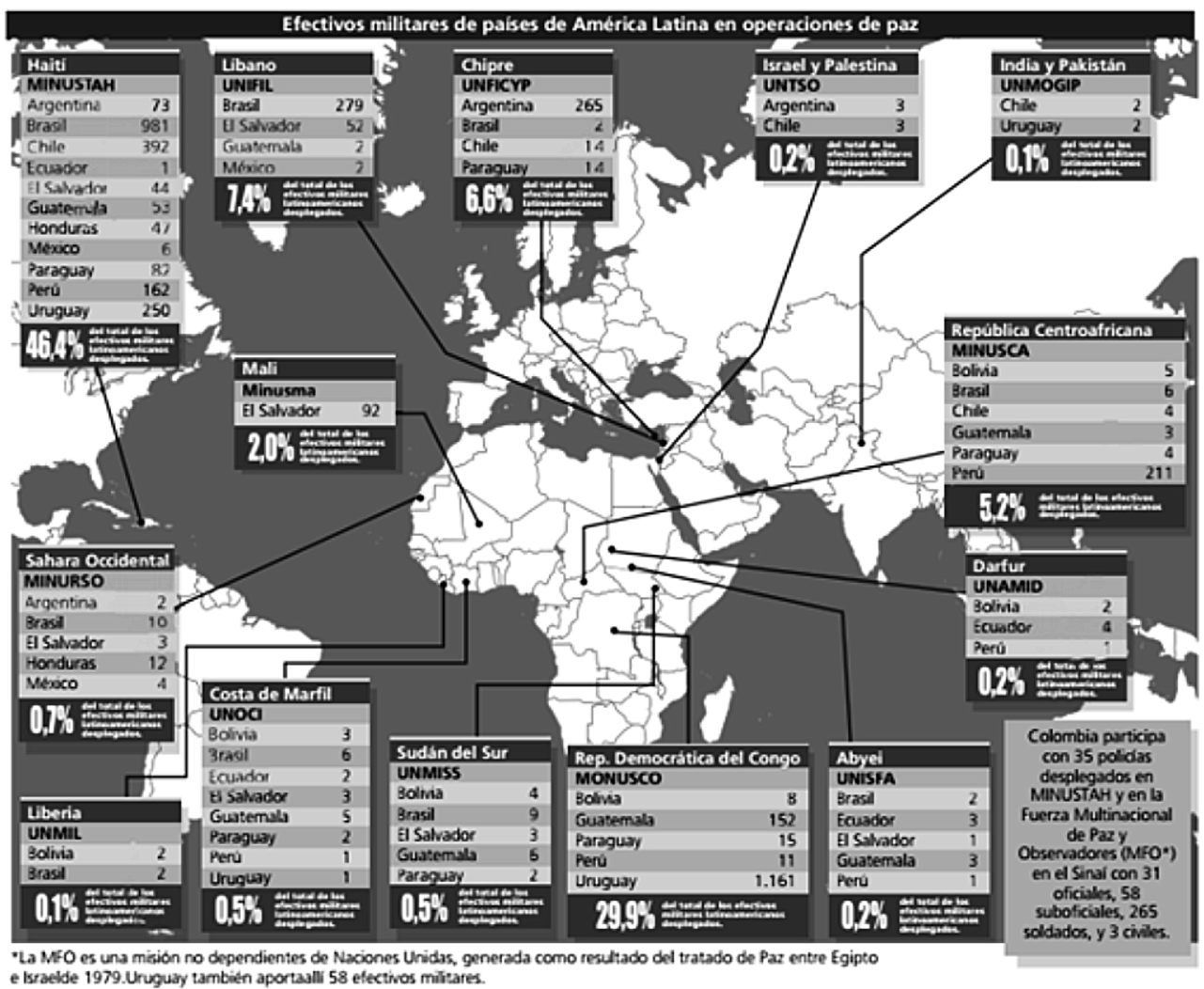

Figura 10. Efectivos militares de países de América Latina en misiones de paz

Fuente: Resdal (2016b, p. 64).

Al respecto, el caso colombiano es muy significativo. La ocupación plena de sus FAS en un conflicto interno de larga duración ha impedido su participación plena en misiones de paz. Sin embargo, con la firma de la paz, las FAS diseñadas para el siglo XXI contemplan su participación en dichas misiones. Sin embargo, y pese a esta aspiración, el diseño de este nuevo ejército no está volcado hacia el exterior; por el contrario, se trata de una fuerza multimisión que tiene asignadas numerosas tareas en el ámbito interno. De este modo, ante la previsible reducción del tamaño del ejército, no parece probable que Colombia pueda hacer una gran aportación a la seguridad internacional en los años venideros, si ha de volcar buena parte de sus esfuerzos en el ámbito interno (Alda, 2016b).

\section{La cooperación y la integración} regional como medio de proyección internacional

La otra referencia adoptada para comprobar las limitaciones de la proyección 
internacional de la región, en materia de seguridad y defensa, es la cooperación intrarregional e internacional. En este ámbito, el principal problema es la falta de confianza, mediante la cual se puedan construir vínculos de cooperación. Esta desconfianza, generada por el peso permanente de una visión soberanista, ha limitado los objetivos y el desarrollo de las iniciativas relacionadas con la integración, en el ámbito de la seguridad y de la defensa. Ciertamente, hay un discurso retórico sobre la necesidad de dicha integración, repetida de manera mecánica por todos los representantes gubernamentales, pero los resultados no terminan de concretarse.

En el ámbito de la defensa, ningún organismo hemisférico ${ }^{1}$ ni latinoamericano tiene una estructura militar común, ni en las organizaciones hemisféricas. En efecto, cualquier tentativa formulada en este sentido ha fracasado siempre, tanto en la Organización de Estados Americanos (OEA), como en la Unasur (Alda y Gómez, 2012) y pese a las propuestas de Hugo Chávez tampoco prosperó en el seno de la Alternativa Bolivariana para los pueblos de nuestra América (ALBA) (Alda, 2012b). Tampo- co hay un sistema regional de defensa ni un pacto de seguridad regional. El Tratado Interamericano de Asistencia Recíproca $(T I A R)^{2}$ representaría este pacto; sin embargo, pese a tener vigencia, no tiene viabilidad desde hace tiempo y ha quedado obsoleto.

En cuanto a los organismos o iniciativas relacionadas con la seguridad y la defensa más sólidas, desarrolladas en el seno de los organismos mencionados, se han llevado a cabo en la OEA, creada en 1948. Sin embargo, no parece que la antigüedad explique mayor nivel de institucionalización alcanzado en este organismo, sino que hay un diseño premeditado para alcanzar el nivel de institucionalización adquirido. Pese a todas sus debilidades y críticas, procedentes fundamentalmente desde la región latinoamericana, la OEA es el organismo de coordinación más sólido y activo de la región (Alda, 2008b), también en materia de seguridad y defensa ${ }^{3}$.

Claro está, hay proyectos subregionales, como la Unasur, y regionales, por ejemplo, la Celac, que proporcionan el marco idóneo para la proyección in-

\footnotetext{
Se entiende por espacio hemisférico a Canadá, Estados Unidos y América Latina y el Caribe. http://www.oas.org/juridico/spanish/tratados/b-29.html

Algunas de las iniciativas de la OEA en materia de seguridad y defensa son: la Secretaria de Seguridad Multidimensional de la OEA, que actualmente es la Secretaria Técnica de los Ministros de Seguridad Pública de las Américas, de la Conferencia de Ministros de Defensa; coordina la Junta Interamericana de Defensa; la Comisión Interamericana para el Control y Abuso de Drogas. También ha organizado el Comité Interamericano contra el terrorismo; la Convención Interamericana contra la Fabricación llícita del Tráfico de Armas de Fuego, municiones, explosivos. El Plan Hemisférico contra la Delincuencia Organizada Transnacional; la Convención Interamericana sobre Transparencia y adquisición de armas convencionales; el programa de asistencia integral en las minas antipersonales y el Observatorio de las Tendencias del Crimen y la Violencia.
} 
ternacional como actor global a América Latina. En este sentido, la existencia de estas iniciativas no deja de mostrar la importancia de los pasos dados por la región, desde principios de 2000. No solo eso, tan importante o más que el desarrollo de estas iniciativas es la propuesta que justifica su creación. La razón de ser tanto de la Celac, como de la Unasur es lograr la autonomía regional de cualquier potencia internacional y tener una voz propia. En consecuencia, este argumento existencial es idóneo para favorecer la presencia internacional de América Latina como un actor global autónomo. En coherencia con ese planteamiento genérico, se crearon el Consejo de Defensa y el Consejo de Seguridad de la Unasur, mediante los cuales es posible construir ese espacio estratégico autónomo, desde los ámbitos de la seguridad y la defensa. Las anteriores iniciativas son inéditas en la región, aunque lo cierto es que los resultados y los avances de estos consejos no han estado a la altura de las expectativas forjadas cuando se crearon en 2008 y 2012, respectivamente (Malamud, 2007,2010 y 2015).

Además de estas iniciativas, deben ser mencionadas otras con diferente alcance y objetivos (figura 11).

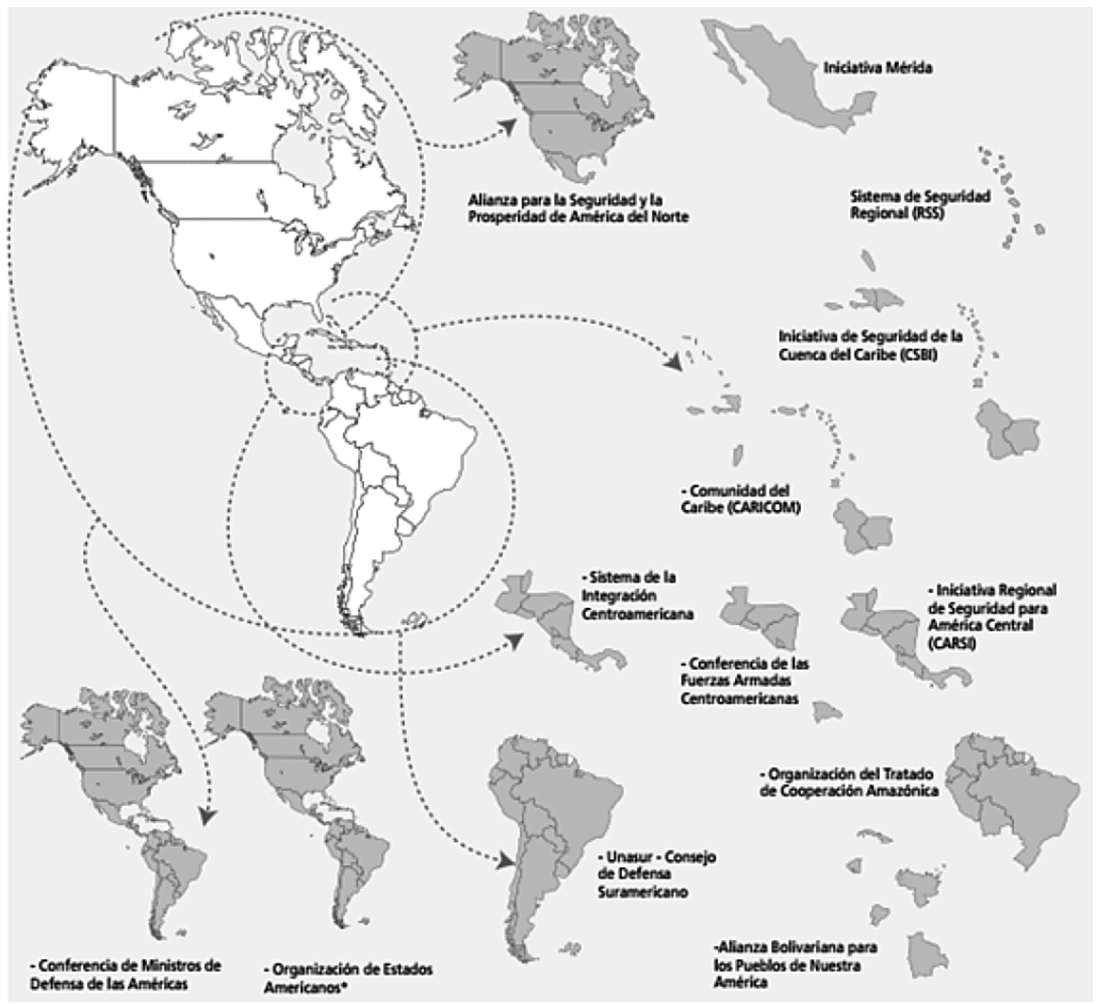

Figura 11. Organismos e iniciativas en el ámbito de la seguridad y la defensa

Fuente: Resdal (2016b, p. 50). 
Respecto a los acuerdos de cooperación que puedan darse entre los países de la región, hay dos constantes que ponen de manifiesto sus limitaciones. Por un lado, la falta de desarrollo y cumplimiento en lo acordado y, por el otro, el carácter bilateral y no multilateral de estos. Esto indicaría de nuevo una considerable desconfianza, que impide dar respuesta a conflictos que ya no son ni entre Estados ni bilaterales. El combate de las nuevas amenazas, bajo una visión local o nacional, está abocado al fracaso y, a lo sumo, a desplazar el problema a los países vecinos, pero no a resolverlo, como se ha contemplado en páginas anteriores.

Si esto es en lo que respecta a la cooperación intrarregional, no es muy diferente en la exrtaregional. Como ya se ha dicho, esta cooperación se desarrolla particularmente con Estados Unidos, pero igualmente de manera bilateral. Valga como ejemplo el Plan Mérida, inicialmente firmado con México, o el Plan Colombia, otro acuerdo de cooperación bilateral.

Con Europa los retos en cooperación en materia de seguridad y defensa siguen siendo muchos y se han iniciado más tarde que en otras áreas. En este punto no pueden olvidarse otros actores internacionales, presentes en la región más recientemente, como Rusia, China e Irán, con quienes se han firmado también acuerdos, igualmente bilaterales, a los que no cabe restar importancia, pero ninguno de ellos trascendental para resolver los problemas de seguridad de la región. El siguiente mapa de la figura 12 da una idea del nivel de relaciones con otras regiones.

\section{Conclusiones}

Las referencias de análisis adoptadas, en esta reflexión, han permitido poner de manifiesto la afirmación que se adelantaba a su inicio. Los procesos de integración en marcha y la cooperación intra y extraregional no tienen suficiente desarrollo para favorecer la suficiente conciencia de unidad necesaria para hacer posible que la región sea un actor internacional, en el ámbito de la seguridad y la defensa. Lo anterior es un aspecto que contribuiría de manera fundamental a resolver los propios problemas de seguridad que comparte la región, en relación con las amenazas transnacionales que padece.

El exceso de nacionalismo es el principal obstáculo para esta meta, pues genera el efecto contrario. Así, pese al discurso oficial de todos los Gobiernos latinoamericanos que, de manera mecánica y retórica, reiteran la necesidad de integración y cooperación, en la práctica, la toma de decisiones esta mediatizada por una concepción nacionalista, cuyo particularismo da lugar a la división y a la fragmentación. Estos son factores que de manera permanente limitan el avance de la integración y de la cooperación, y en consecuencia de la configuración de la región como actor.

Ciertamente, la integración en el ámbito de la seguridad y defensa no es fácil. Hay otros ejemplos que ponen de ma- 


\section{Vinculos con otros continentes}

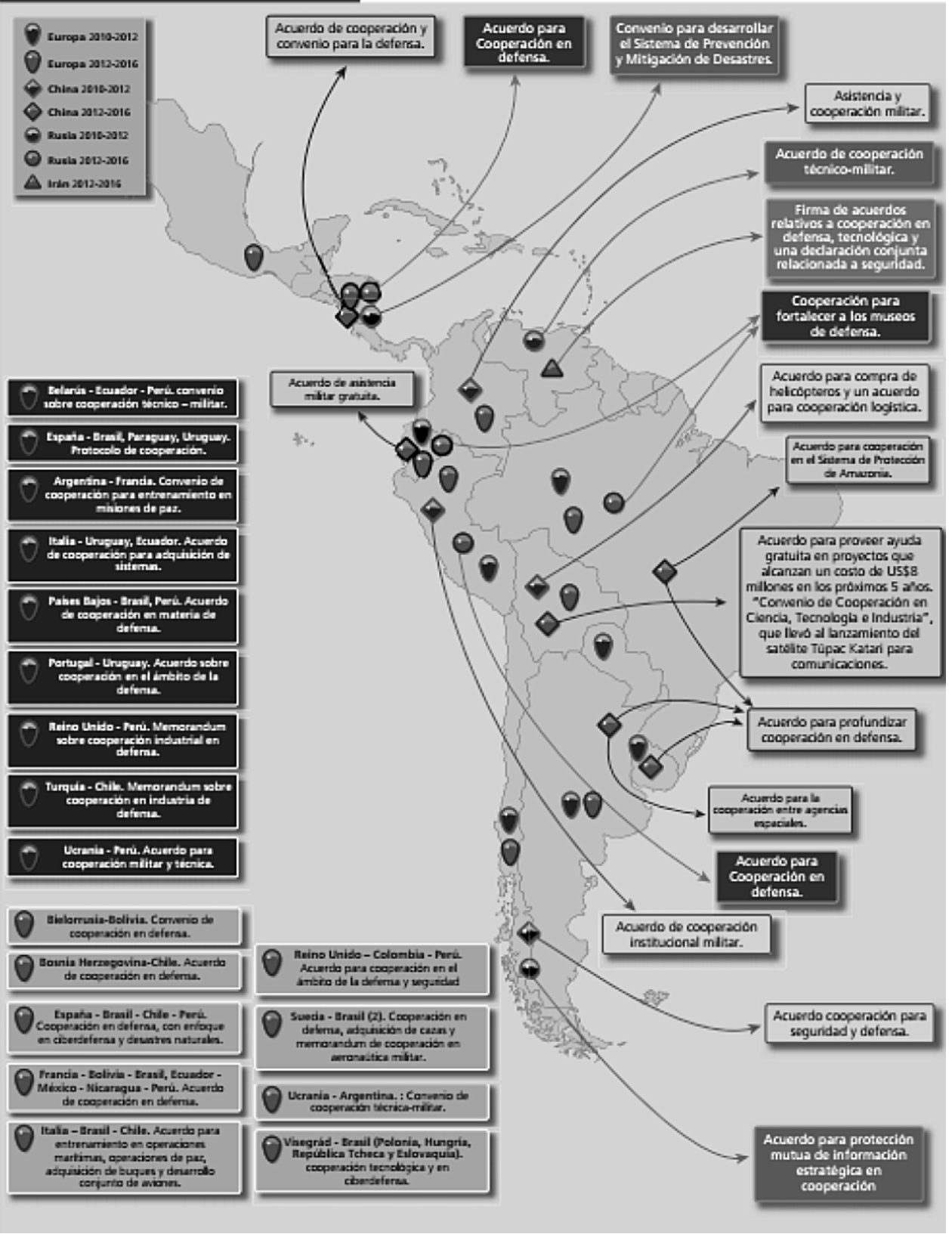

Figura 12. Acuerdos con otros países extraregionales

Fuente: Resdal (2016b, p. 50). 
nifiesto las resistencias de los Estados. Para estos, la seguridad y la defensa se contemplan como manifestaciones intrínsecas a su poder soberano, de ahí las resistencias a hacer "concesiones" en estos espacios; la Unión Europea es un buen ejemplo de ello. Mientras que los avances en integración en materia económica y comercial han sido muy destacables, no se han dado ni a la misma velocidad, ni con la misma intensidad en el espacio de la seguridad y la defensa.

En relación con América Latina, la existencia de obstáculos no significa que no haya tenido lugar ningún avance. Desde una concepción de integración autónoma y propia, en relación con otras potencias, se ha desarrollado el mejor marco posible para configurarse como un actor regional.

En este nuevo regionalismo estarían enmarcados la Unasur o la Celac, organismos que ponen de manifiesto los avances de las relaciones intrarregionales y muy particularmente en el ámbito de la seguridad y la defensa. De hecho, este nuevo regionalismo contempla de manera particular este espacio, a diferencia de propuestas de integración anteriores. Sin embargo, las posibilidades de desarrollar estas iniciativas siempre se verán limitadas, si se tiene en cuenta que, en última instancia, el objetivo de estos organismos es "fortalecer" la soberanía de los países miembros, como consta en el Acta Constitutiva de la Unasur y en el Estatuto del Consejo de Defensa Suramericano (Unasur, 2011, 2008).
Estas limitaciones impiden profundizar en la cooperación intrarregional, lo que pone de manifiesto nuevamente la persistencia de una visión particularista que desconfía de la cooperación vecinal y que impide tomar auténtica conciencia de la necesidad de la cooperación intra estatal. Más allá de la retórica, en la práctica predomina la búsqueda de soluciones restringidas al marco nacional, en un escenario de inseguridad que exige la cooperación intraestatal.

El desarrollo extraordinario del crimen organizado trasnacional, en la región, no ha contribuido a dar una respuesta con la misma dimensión y alcance, a través de la integración y de la cooperación interestatal. Pese a todo, el enfoque de las políticas de seguridad continúa siendo de dimensión nacional, lo que en última instancia limita necesariamente los resultados de dichas políticas o incluso provoca efectos contraproducentes. Sin la cooperación intraestatal, por muchos que sean los esfuerzos humanos y materiales realizados siempre serán limitados, ya que no se corresponden con la dimensión de la amenaza.

Desde esas políticas de dimensión nacional, el nivel de inseguridad existente ha dado lugar a que los trabajos de todas las fuerzas de seguridad se vuelquen en la seguridad interior. Policías y fuerzas armadas intentan controlar los altos índices de criminalidad, lo que redunda en el espacio tradicional de actuación de dichas fuerzas; esa dedicación de todos los recursos 
y fuerzas al ámbito nacional limita necesariamente la participación de estas en misiones de paz. Este "ensimismamiento" hacia el interior es un factor que, a excepción de países del Cono Sur, vuelve a reincidir en la idea de unas fuerzas de seguridad "ocupadas" plenamente en el espacio nacional, y se vuelve a caer en la reproducción del nacionalismo señalado.

Esto no significa que no sea posible llegar a acuerdos y posiciones comunes, a partir de los cuales se puedan sentar las bases para una actuación conjunta como actor internacional. La reivindicación latinoamericana, sin fisuras, liderada por Brasil, en relación con el regreso de Cuba a la comunidad hemisférica, pone en evidencia esta posibilidad; factor que ha contribuido al restablecimiento de las relaciones entre la isla caribeña y Estados Unidos (Alda, 2015a). No obstante, por el momento, predominan los obstáculos y la voluntad, y las iniciativas adoptadas no son suficientes.

La reproducción permanente de un enfoque estratégico determinado por una visión marcadamente nacionalista y unas FAS volcadas en el territorio nacional dificulta la posibilidad de esta proyección conjunta internacional. Esa misma visión es la que limita el desarrollo de una cooperación, tanto intraregional, como internacional, que no solo proyectaría la región hacia el exterior, sino que además contribuiría a resolver las principales amenazas transnacionales que afectan, de forma grave, a la mayoría de sus países.

\section{Referencias}

Alda, S. (2008a). La participación de las Fuerzas Armadas en los proyectos del populismo-nacionalista en América Latina. Real Instituto Elcano. Recuperado de http://www. realinstitutoelcano.org/wps/portal/ rielcano_es/contenido?WCM GLOBAL_CONTEXT =/elcano/elcano es/zonas es/DT36-2008

Alda, S. (2008b). LA OEA: un actor regional en la gestión de crisis. Logros y limitaciones. En E. Vega (Comp.), Realidades y perspectivas de la gestión internacional de crisis (pp. 6998). Madrid: Instituto Universitario Gutiérrez Mellado [IUGM].

Alda, S. (2012a). La participación militar en el combate de la violencia criminal. En E. Iglesias (Coord.), Los desafíos de la seguridad en Iberoamérica (198-232) Madrid: IEEE, Instituto Universitario Gutiérrez Mellado [IUGM]. Recuperado de http://www.ieee.es/Galerias/fichero/cuadernos/CE_158_DesafiosSeguridadlberoamerica.pdf

Alda, S. (2012b). El ALBA y su propuesta de integración militar. En S. Alda y H. Saint-Pierre (Coords.), Gobernabilidad y democracia. Defensa y transiciones de Brasil y España (pp. 243-279). Santiago de Chile: RIL.

Alda, S. (2013). La guerra contrarrevolucionaria: un factor de predisposición al hecho. Análisis comparado Argentina, Chile y Guatemala. En A. Gil (Dir.), Intervención delictiva y derecho penal internacional. Reglas de atribución de la responsabilidad 
en crímenes internacionales (pp. 25-54). Madrid: Dykinson.

Alda. S (2014). Estado y crimen organizado en América Latina. Posibles relaciones y complicidades. Revista Política y Estrategia, (124), 73-107.

Alda, S. (2015a). América Latina un territorio de paz, ¿con aspiraciones a llegar a ser un actor global? En S. Alda y S. Ferreira (Coords.), La multidimensionalidad de la seguridad nacional: retos y desafíos de la región para su implementación (pp. 103-127). Madrid: Instituto Universitario Gutiérrez Mellado [IUGM], Secretaria de Seguridad y Defensa (Sedena, Perú). Recuperado de http://iugm.es/wp-content/ uploads/2016/06/2015-1325 Interiores_SIN_MARCAS.pdf

Alda, S. (2015b). La debilidad del imperio de la ley en América Latina: un factor para entender la implantación del crimen organizado. Revista Española de Ciencia Política, (37). Recuperado de http://recyt. fecyt.es/index.php/recp/article/ view/37649

Alda, S. (2016a). El combate a la corrupción para combatir el crimen organizado. Recuperado de http://www.realinstitutoelcano.org/wps/portal/rielcano_es/ contenido?WCM_GLOBAL_CONTEXT =/elcano/elcano_es/zonas_es/ dt6-2016-aldamejias-combate-corrupcion-crimen-organizado

Alda, S. (2016b). Las posibilidades de transformación de las fuerzas de seguridad en Colombia, tras el postconflicto. Revista del Instituto Español de Estudios Estratégicos, (7). Recuperado de http://revista.ieee. es/index.php/ieee/article/view/214

Alda, S. (s. f.). Tráficos ilícitos y redes criminales entre América Latina y Europa. Real Instituto Elcano (en prensa).

Alda, S. y Gómez, V. (Eds.). (2012). El concepto y las relaciones multilaterales de seguridad y defensa en el contexto de la Unasur. Madrid: Instituto Universitario Gutiérrez Mellado [IUGM]. Recuperado de http://iugm.es/uploads/tx_iugm/ UNASUR.pdf

Bagley, B. (2012). Drug trafficking and organized crime in the Americas: Major Trends in the Twenty-First Century. Washington, D. C.: Woodrow Wilson Center.

Bartolomé, M. (2009). Las fuerzas armadas sudamericanas y las perspectivas de cooperación en la lucha contra el terrorismo y el crimen organizado. Estudios Internacionales, (164), 7-30. Recuperado de http:// www.revistaei.uchile.cl/index.php/ REl/article/viewFile/12595/12900

Benítez, R. (2008), "América Latina y la seguridad internacional. El caso de Haití y las misiones de paz". Revista Enfoques. Año 6, no 8, Primer-Semestre. file://C:/Users/ Sonia/Downloads/Dialnet-AmericaLatinaYLaSeguridadInternacional-2722945\%20(4).pdf.

Buscaglia, E. (2014). "¿Argentina es el nuevo paraíso para el narcotráfico?". Semana.com, http://www. 
semana.com/mundo/articulo/argentina-un-nuevo-paraiso-para-el-narcotrafico/393282-3.

Campero, Jose Carlos, "El crimen organizado (vinculado al narcotráfico) en Bolivia", en Niño, Catalina (ed.), Crimen organizado y gobernanza en la región andina: cooperar o fracasar, Friederich Ebert-ILDIS, Quito, 2012.

Comisión Global de Política de Drogas. (2011). http://www.edrogas.es/c/document_library/ get file?uuid =4f0a 2cb6-3c01446c-9be6-3804e8a35b38 \&grou$\mathrm{pld}=10156$

Council on Hemispheric Affairs (2 de diciembre de 2013). The Relationship Between Italian Mafias and Mexican Drug Cartels - Part 1: A Comparison. Recuperado de http:// www.coha.org/the-relationship-between-italian-mafias-and-mexican-drug-cartels-part-1-a-comparison/

Dinatale, M. (8 de agosto de 2016). Macri busca apoyo externo y de las FF.AA. para combatir el narcotráfico. La Nación. Recuperado de http://www.lanacion.com. ar/1925857-macri-busca-apoyo-externo-y-de-las-ffaa-paracombatir-el-narcotrafico

Gagne, D. (2016). "Cartografía de la diáspora del narcotráfico colombiano, InsightCrime, http:// es.insightcrime.org/analisis/cartografia-diaspora-narcotrafico-COlombiano.

European Monitoring Centre for Drugs and Drug Addiction [EMCDDA]
(2016). EU Drug Markets Report: In Dept Analisys. Recuperado de http://www.emcdda.europa.eu/ system/files/publications/2373/ TD0216072ENN.PDF

Garzón, J. C. y Eric, O. (Eds.) (2013). La diáspora criminal: la difusión transnacional del Crimen Organizado y cómo contener su expansión. Washington D. C.: Woodrow Wilson Center. Recuperado de www. wilsoncenter.org/sites/default/files/ LA_DIASPORA_CRIMINAL.pdf

Geffray, Ch. (2001). Drug Trafficking and the State. International Social Science Journal, 53(169), 421-426.

Gómez de la Torre, A. (2016). Hacia una comunidad de seguridad entre el Perú y sus vecinos. ¿Es viable y realista? En VV.AA. El proceso de construcción de una comunidad en seguridad entre Bolivia, Brasil, Chile, Colombia, Ecuador y Perú (pp. 11-34). Lima: Universidad Católica del Perú, Konrad Adenauer.

González, J. (2014). La contribución de Uruguay para operaciones de paz de Naciones Unidas: acerca de las motivaciones y la interpretación de su record. Revista Uruguaya de Ciencia Política. 23(1). Recuperado de http://www.scielo.edu.uy/scielo.php?script $=$ sci arttext\&pid=S1688-499X201 4000100002.

Kalil, S. (s. f). Forças Armadas e Gobernabilidade no Goberno Lula. Recuperado de www.resdal.org/ producciones-miembros/artmathias.pdf. 
Lafferriere, G. H. y Soprano, G. (2016). Participación militar argentina en misiones de paz. Desafíos para la política de Defensa e influencia en la organización y funcionamiento en las Fuerzas Armadas. 19902013. Relaciones Internacionales, (50), 273-297.

Le Dantec, P. (2006). Chile y las operaciones de paz. Estudio comparado de la política exterior de los tres gobiernos concertacionistas. De la inserción internacional a la participación en Haití. Santiago de Chile: Academia Nacional de Estudios Políticos y Estratégicos [Anepe]. Recuperado de http://www.anepe. cl/wp-content/uploads/LIBRO-ANEPE-N\%C2\%BA-15.pdf

Lupsha, P. (2002). Organized Crime: Rational Choice not Ethnic Group Behavior: a Macro Perspective. Law Enforcement Intellegence Analysis Digest, 1-8.

Malamud, C. (2007). Los acuerdos regionales latinoamericanos en el ámbito de la seguridad y la defensa: los retos y desafíos de la cooperación. En Ministerio de Defensa (Ed.), Seguridad y defensa en Iberoamérica. Posibilidades actuales para la cooperación (pp. 11-26). Madrid: Ministerio de Defensa. Recuperado de http://www.defensa.gob.es/ceseden/Galerias/destacados/publicaciones/docSegyDef/ ficheros/015_SEGURIDAD_Y_DEFENSA EN IBEROAMERICA. POSIBILIDADES ACTUALES PARA LA COOPERACION.pdf
Malamud, C. (2010). El consejo suramericano de defensa: entre grandes expectativas y una realidad compleja y fraccionada. En Ministerio de Defensa (Ed.), La creación de en el marco de la seguridad y la defensa (pp. 65-73). Madrid: Ministerio de Defensa.

Malamud, C. (26 de octubre de 2015). Integración y cooperación regional en América Latina: diagnóstico y propuestas. Real Instituto Elcano. Recuperado de http://www.rea$\underline{\text { linstitutoelcano.org/wps/portal/ }}$ rielcano es/contenido?WCM GLOBAL_CONTEXT=/elcano/elcano_es/zonas_es/america+latina/ dt15-2015-malamud-integracioncooperacion-regional-americalatina-diagnostico-propuestas

McDermott, J. (16 de octubre de 2014). Bolivia: el nuevo epicentro del narcotráfico en Suramérica. Recuperado de http:// es.insightcrime.org/investigaciones/bolivia-nuevo-epicentro-narcotrafico-suramerica

Naciones Unidas (s. f.). Países que aportan contingentes de soldados y policías. Recuperado de http:// www.un.org/es/peacekeeping/resources/statistics/contributors.shtml

Palma, H. (2010). La cooperación fronteriza en el área Andina. En S. Alda y V. Ricaurte (Eds.), El concepto y las relaciones multilaterales de seguridad y defensa en el contexto de la Unasur (pp. 295-320). Madrid: Instituto Universitario Gutiérrez Mellado [IUGM]. 
Perry, M. (2009). Las Fuerzas Armadas de Chile y su proceso de integración a las operaciones de paz. UNISCI Discussion Papers, (21). Recuperado de https://www.ucm.es/ data/cont/media/www/pag-72507/ UNISCI\%20DP\%2021\%20-\%20PERRY.pdf

Radio ONU. (23 de marzo de 2015). La contribución de América Latina a las misiones de paz de la ONU es cada vez mayor. Recuperado de http://www.unmultimedia.org/radio/spanish/2015/03/ la-contribucion-de-america-latina-a-las-misiones-de-paz-dela-onu-es-cada-vez-mayor/\#. WJtheDvhDIU

Red de Seguridad y Defensa de América Latina (2016a). Índice de Inseguridad Pública, http://www. resdal.org/assets/indice_2016 dossier_a-corr.pdf.

Red de Seguridad de Defensa y América Latina (Resdal). (2016b). Atlas Comparativo de la Defensa en América Latina y Caribe. Buenos Aires: Autor. Recuperado de http:// www.resdal.org/wordpress_a/ wp-content/plugins/pdfjs-viewershortcode/pdfjs/web/viewer. php?file $=$ http $\% 3 \mathrm{~A} \% 2 \mathrm{~F} \% 2 \mathrm{Fwww}$. resdal.org\%2Fwordpress_a\%2Fwpcontent $\% 2$ Fuploads $\% 2 \mathrm{~F} 2016 \% 2 \mathrm{~F} 1$ 1\%2Fatlas-2016-esp-completo.pdf $\underline{\& \text { download }=\text { true } \& \text { print }=\text { true } \& \text { op }}$ enfile $=$ false

Rial, J. (s. f.). La participación argentina en las Operaciones de Mantenimiento de la Paz de las Naciones
Unidas desde el advenimiento de la Democracia hasta la 2011. Universidad de la Plata. Recuperado de http://www.iri.edu.ar/images/Documentos/maestria/tesis/tesis rial.pdf

Rice, S. y Patrick, S. (2008). Index of States weakness in the developing world. The Brookings Institution. Recuperado de https://www. brookings.edu/wp-content/uploads/2016/06/02 weak states index.pdf

Semana (16 de enero de 2016). La macabra alianza de los carteles de Colombia y México. Semana. Recuperado de http://www.semana. com/nacion/articulo/la-macabraalianza-de-los-carteles-de-colombia-mexico/456871-3.

Sepúlveda, I. y Alda. S. (Coords.) (2008). La defensa como una política pública en América Latina. Madrid: Instituto Universitario Gutiérrez Mellado [IUGM].

Logan, S. (2013). Rastreando la presencia internacional del cartel de Sinaloa. InsightCrime. Recuperado de http://es.insightcrime.org/ analisis/rastreando-la-presenciainternacional-de-la-federacion-desinaloa\#ft18

Pachico, E. (2012). Mexico cartels operate in 16 countries: Report. InsightCrime. Recuperado de http:// www.insightcrime.org/news-analysis/mexico-cartels-connectionsabroad

Ramalho, A. (2016). Tres pasos para avanzar en la construcción de una comunidad en seguridad en Sur- 
américa. En VV.AA. El proceso de construcción de una comunidad en seguridad entre Bolivia, Brasil, Chile, Colombia, Ecuador y Perú (pp. 101-130). Lima: Universidad Católica del Perú, Konrad Adenauer.

Suárez, G. (Coord.) (2005). Crisis locales y seguridad internacional. Cuadernos de Estrategia, (131). Recuperado de http://www.ieee. es/Galerias/fichero/cuadernos/CE131.pdf

Tokatitlan, J. G. (2011). Latinoamérica y sus "alianzas" extrarregionales: entre el espejismo, la ilusión y la evidencia. En D. Wollrad, G. Maihold y M. Mols (Eds.), La agenda internacional de América Latina: entre nuevas y viejas alianzas (pp. 139-162). Buenos Aires: FriedrichEbert-Stiftung.

Unión Sudamericana de Naciones (Unasur) (11 de marzo de 2011).
Tratado Constitutivo de la Unasur. Recuperado de http://www. unasursg.org/images/descargas/ DOCUMENTOS\%20CONSTITUTIVOS\%20DE\%20UNASUR/TratadoUNASUR-solo.pdf

Unión Sudamericana de Naciones (Unasur) (11 de diciembre de 2008). Estatuto del Consejo de Defensa Suramericano. Recuperado de http://www.unasursg.org/images/ descargas/ESTATUTOS\%20CONSEJOS\%20MINISTERIALES\%20 SECTORIALES/ESTATUTO $\% 20$ CONSEJO\%20DE\%20DEFENSA.pdf

Yagoub, M. (16 de septiembre de 2016). Arresto de ciudadano serbio señala conexiones entre Suramérica y los Balcanes. InsightCrime. Recuperado de http://es.insightcrime. org/analisis/arresto-ciudadano-serbio-senala-conexiones-suramerica$\underline{\text { balcanes. }}$ 